\title{
Unique stressors in a global pandemic: a mixed methods study about unique causes of distress among healthcare team members during COVID-19
}

\author{
Alejandra Colón-López ${ }^{1,2}$, Katherine A. Meese ${ }^{2,3}$, Aoyjai P. Montgomery ${ }^{4}$, Patricia A. Patrician ${ }^{5,6}$, \\ David A. Rogers ${ }^{2}$, Greer A. Burkholder ${ }^{7}$
}

${ }^{1}$ Department of Sociology, University of Alabama at Birmingham, Birmingham, AL, USA; ${ }^{2}$ UAB Medicine Office of Wellness, University of Alabama at Birmingham, Birmingham, AL, USA; ${ }^{3}$ Department of Health Services Administration, University of Alabama at Birmingham, Birmingham, AL, USA; ${ }^{4}$ Office of Research and Scholarship, School of Nursing, University of Alabama at Birmingham, Birmingham, AL, USA; ${ }^{5}$ Rachel Z. Booth Endowed, School of Nursing, University of Alabama at Birmingham, Birmingham, AL, USA; ${ }^{6}$ Family, Community and Health Systems Department, University of Alabama at Birmingham, Birmingham, AL, USA; ${ }^{7}$ Division of Infectious Diseases, University of Alabama at Birmingham, Birmingham, AL, USA

Contributions: (I) Conception and design: A Colón-López, KA Meese, DA Rogers; (II) Administrative support: DA Rogers; (III) Provision of study materials or patients: KA Meese, DA Rogers; (IV) Collection and assembly of data: KA Meese, A Colón-López, DA Rogers, GA Burkholder; (V) Data analysis and interpretation: A Colón-López, KA Meese, AP Montgomery, PA Patrician, GA Burkholder; (VI) Manuscript writing: All authors; (VII) Final approval of manuscript: All authors.

Correspondence to: Alejandra Colón-López, MA. Department of Sociology, University of Alabama at Birmingham, Birmingham, AL, USA. Email: colon92@uab.edu.

Background: Amid the COVID-19 pandemic, healthcare systems experienced significant challenges, including lower revenues from elective procedures, limited supplies, a massive influx of patients and psychologically distressed employees. National reports of well-being showed striking rates of burnout among healthcare workers. Prior research depicted how the pandemic affected all categories of healthcare workers, yet there is little evidence showing what specific factors hinder each type of employee.

Methods: Employees from a large medical center in the Southeastern United States (US) $(n=1,130)$ participated in an online survey, responding to a series of questions about their daily stressors, working conditions, and distress as measured by a 9-item Well-Being Index (WBI), and providing open-ended responses about additional stressors and positive changes in their work. With an analytic sample of 1,037, we used stepwise analysis for each employee group to identify which stressors have a significant association with their overall distress. Using a convergent mixed methods approach, we corroborate our quantitative findings with qualitative themes from the open-ended responses.

Results: Among all types of employees i.e., physicians, nurses, Advanced Practice Providers (APPs), Clinical support staff and Non-clinical staff, moral distress was associated with higher WBI distress. Qualitative themes showed employees were mainly concerned with quality of and access to care for patients. Stress triggered by heavy workload in the setting of increased pandemic-related responsibilities and decreased personnel was associated with a high level of WBI distress among all types of employees, whereas other significant stressors differed by role.

Conclusions: The COVID-19 pandemic created a myriad of work and non-work-related stressors hindering all healthcare workers' psychological well-being differently. Working conditions and responsibilities for each role are unique. Institutional policies must contemplate the distinctiveness of stressors and distress across employee sub-groups to properly mitigate psychological distress.

Keywords: Well-being; COVID-19; stressors; burnout; distress 
Received: 16 September 2021; Accepted: 26 January 2022; Published: 25 September 2022.

doi: 10.21037/jhmhp-21-69

View this article at: https://dx.doi.org/10.21037/jhmhp-21-69

\section{Introduction}

The COVID-19 pandemic has placed unprecedented strain on healthcare workers worldwide, adding to the mental health burden of a workforce already more likely to suffer from adverse mental health outcomes than employees in many other sectors or the general public. Even prior to the COVID-19 pandemic, a growing body of literature demonstrated higher prevalence of depression (1-3), anxiety, suicide, symptoms of post-traumatic stress disorder, and alcohol and prescription drug abuse among healthcare workers (4), although the focus has mostly been on nurses and physicians and there is variation by gender and work role.

In addition, prevalence of burnout among physicians and nurses is high and in recent years there has been increased interest in moral injury among healthcare workers as a result of work constraints which force them to provide care in a way that violates their moral beliefs (5-7). These factors can result in decreased productivity, higher rates of absenteeism, increased risk of medical errors and patient safety concerns (8-13). Although there are limited pre-pandemic data on the mental health of Non-clinical staff, a New Zealand study reported a significant impact of job demand stressors such as role conflict and role overload on emotional exhaustion among Non-clinical healthcare service workers (14). A prepandemic Italian study found that $68 \%$ of clinical research coordinators reported stress negatively impacting their work performance and on average they experienced an intermediate level of burnout (15).

Studies from prior pandemics reveal adverse mental health consequences for healthcare workers (16). While there are few longitudinal studies that evaluate pre- versus post-COVID-19 pandemic distress among healthcare workers, The physicians Foundation Survey found that $61 \%$ of physicians surveyed in the United States (US) reported often experiencing feelings of burnout in 2021 as opposed to $40 \%$ in 2018. In contrast, the Medscape National Physician Burnout and Suicide Report 2021 found that the proportion of physicians reporting burnout was similar to 2019 (42\% versus $44 \%$ ) and that $79 \%$ of physicians with burnout reported their burnout began prior to the pandemic. However, there was a shift in specialties with highest proportion of physicians reporting burnout to critical care, rheumatology and infectious diseases, and $21 \%$ of physicians with burnout reporting it began after the pandemic $(17,18)$.

Myriad stressors have impacted healthcare workers over the course of the COVID-19 pandemic, with variation by demographics and work role. These include but are not limited to inadequate access to personal protective equipment (PPE), fear of or actual personal infection with COVID-19, concerns about infecting a family member, caring for critically ill COVID-19 patients, social isolation, childcare, increased workload, understaffing, deployment to work outside their skillset and training, reduction in income or job loss, and adapting to telemedicine (19-23). These stressors span both professional and personal domains; some are related to providing patient care whereas others impact non-clinical work.

Over the last year there has been a sharp increase in studies focused on the mental health of healthcare workers in the context of the psychological impact of the COVID-19 pandemic. Overall, these have demonstrated high prevalence of depression, anxiety, insomnia, distress, and burnout (24). However, only a limited number of studies were conducted in the US, which has more COVID-19 cases and deaths than any other country (25). As of September 12, 2021, there have been 550,638 cases of COVID-19 among US healthcare workers and 1,752 have died (26). In addition, while some studies have evaluated a limited number of stressors, few have focused comprehensively on the broad array of work and nonwork stressors taxing healthcare workers, the association of specific stressors with mental health outcomes, and how these may vary by job role.

Previously we reported a high prevalence of distress among healthcare workers at a large healthcare system in the Southeastern US during the COVID-19 pandemic and the work and non-work factors, including stressors, associated with distress across all types of healthcare workers (27). We found that increased job demands or responsibilities, heavy workload or long hours, higher frequency of moral distress, and loneliness or social isolation were associated with higher levels of distress. However, we hypothesize that the impact of specific factors 
would be heterogeneous across different roles within the healthcare team. Understanding such differences would allow healthcare systems to take a more nuanced approach to mitigating distress and improving employee well-being during and after the COVID-19 pandemic. Utilizing a mixed methods approach, we evaluated the association of specific work and non-work-related stressors and other factors with employee distress, stratified across different types of healthcare employees. We present the following article in accordance with the SURGE reporting checklist (available at https://jhmhp.amegroups.com/article/ view/10.21037/jhmhp-21-69/rc).

\section{Methods}

\section{Study design}

This study was conducted in accordance with the Declaration of Helsinki (as revised in 2013). This study was approved by the Institutional Review Board of the University of Alabama at Birmingham (No. IRB300005398) and informed consent was taken from all of the participants. The survey population for this study included clinical (e.g., physicians, nurses) and Non-clinical (e.g., administrative staff) workers employed by a medical center during the time this survey was administered. In June and July 2020, healthcare employees at a large medical center in the Southeastern US received an online invitation to participate in an anonymous cross-sectional survey. For 3 weeks, potential participants received invitation emails in which we encouraged them to complete our survey. We used a convenience sampling frame to collect our data. Participants were not compensated for completing our survey.

Respondents reported their levels of distress, resilience, and individual and organizational-level factors. Additionally, respondents chose major general work, clinical and non-work stressors from a predetermined list and reported additional stressors through openedended responses. The data that support the findings of this study are available from the corresponding author upon reasonable request.

To corroborate the association between healthcare workers' major stressors during the COVID-19 pandemic and well-being, we employed a convergent mixed methods research (MMR) design (28). In other words, this study had the quantitative and qualitative strands happening simultaneously with equal priority $(29,30)$.

\section{Quantitative analysis}

\section{Dependent variable}

Distress was assessed using the validated 9-item WellBeing Index (WBI) tool $(10,13,31,32)$. This measure has a range of scores from -2 to 9 , with higher scores suggesting greater distress. For the general population, a WBI score equal to or larger than 2 is considered "high distress". High WBI distress scores have been associated with increased risk of burnout, medical errors, poor quality of life, and suicidal ideation $(11,13,33)$.

\section{Independent variables}

The survey collected demographic characteristics including work characteristics such as role, primary work location and whether employee has direct contact with COVID-19 patients. All role categories were recoded into 5 categories: Physician, Nurse, Advanced Practice Provider (APP) (e.g., physician assistants, nurse practitioners, and certified registered nurse anesthetists), Clinical support staff (e.g., lab personnel, social worker, respiratory therapist) and Non-clinical staff (e.g., administrative worker, non-clinical researcher, pastoral service).

Three questions collected information regarding any stressors which participants found most concerning over the past 3 months i.e., there was the ability to select all that applied as well as to write in additional stressors: (I) general work-related stressors including COVID-19 exposure or symptoms requiring testing, personal infection with COVID-19, fear of becoming infected, difficulty obtaining COVID testing, continuing to work despite being at high risk for poor outcome if infected by COVID-19, moral distress, reduction in income, furlough, fear that job loss, furlough, or reduction in income could happen in future, reduced productivity, increased job demands or responsibilities, heavy workload or long hours, working remotely, rapid changes in workflow or policies, general feelings of anxiety or uncertainty, issues concerning race/ ethnicity, and discrimination; (II) stressors related to providing clinical care including high risk of personal exposure to COVID-19 while providing care, shortage of COVID-19 tests for patients, caring for critically ill COVID patients, inadequate PPE, feeling unable to give patients the care or treatment they deserve, patients not able to see family members or friends, uncertainty about how to best treat COVID-19 patients, moral distress, uncertainty of adequate skills if redeployed to an unfamiliar unit or task, scope of practice or supervision changes for self, scope 
of practice or supervision changes for others, reduced productivity, increased responsibilities or job demands, adapting to telemedicine/challenges related to telemedicine, rapid changes in workflows or policies, general feelings of uncertainty, racially-related health disparities or other issues concerning race/ethnicity, discrimination, and societal response to COVID-19; and (III) stressors outside of work including family or close friends with COVID-19, family or friends at high risk for COVID-19 complications if contracted, separation from family or loved ones due to concerns for infecting them, fear of infecting family with COVID-19, spouse or partner with job insecurity, job loss or loss of income, childcare, eldercare, strained relationship with loved one, social isolation or loneliness, general feelings of anxiety or uncertainty, societal response to COVID-19, issues concerning race/ethnicity, discrimination and societal response to issues concerning race/ethnicity.

A single-item measure from the 2018 Veterans Affairs (VA) All Employee Survey (AES) was used to measure moral distress, asking how frequently in the past year the respondent experienced moral distress at work such as being unsure about the right thing to do or unable to carry out what they believed to be the right thing on a 5-point Likert scale, with 5 indicating almost every work day (34).

Work control and decisional involvement were also measured using single-item measures. Decisional involvement is a measure from the 2018 VA AES, asking the degree to which respondents were satisfied with their involvement with decisions that affect their work (34). Work control was adapted from a single-item measure for job control asking to what extent people had control over their work (35). A Likert scale was used with 1 indicating strongly disagree, and 5 indicating strongly agree.

A 3-question series capturing feeling of organizational support was adapted from the 8 -item scale (36), asking the degree to which respondents agreed their organization cared about their satisfaction, well-being and extra efforts and contributions. Each item is scored on a 1-5 Likert scale, resulting in total scores 3-15 with higher scores indicating higher perceived support.

Individual resilience was measured using the 2-item Connor Davidson Resilience Scale (CD-RISC-2), in which respondents rate their ability to adapt to change and bounce back after illness or hardship (37), resulting in a resilience score from $0-8$ with 8 indicating the highest resilience. A 3-question instrument measured participant's perception of team level adjustment to change, known as team resilience (38).

\section{Statistical analysis}

Using Stata V.16.1, ordinal least square (OLS) stepwise regressions were calculated to determine the best model fit for each healthcare worker group (39). Based on the combination of predictors that provided the best model fit for the regression models, mean scores with standard deviations (SD) for decisional involvement, work control, resiliency, team resiliency feelings of organizational support, moral distress, and total count of non-work stressors for each group were calculated as well as percentages of major general work and clinical work for each employee group. Using results from stepwise regression, multivariate regression analysis was conducted to determine the relationship between WBI distress and specific stressors and other work-related predictors.

\section{Qualitative analysis}

NVivo 11 was used to systematically analyze open-ended responses indicating additional general work, clinical work, and non-work stressors, and positive changes or innovations (40). To determine context of open-ended response, respondents' role was not suppressed during all stages of coding. First, line by line coding followed by focused coding was used to identify major stressors and positive changes (41). To corroborate quantitative findings, code segments were selected to represent or contrast quantitative findings. For the meta-inference of this study, a weaving approach was used to present result from both strands (42). To make the integrating process transparent, quantitative, and qualitative results were reported using a joint display.

\section{Results}

In total, 1,130 healthcare employees participated in the survey with a response rate of 18 percent (participants who participated/total of contacted participants). Because of missing information, 93 respondents were excluded from our analysis using listwise deletion. Our analytic sample had 1,037 participants with a mean age of 44 years. More than half of our sample identified as female (68\%), $20 \%$ male, $1 \%$ other, and $11 \%$ preferred not to disclose their gender. In terms of race and ethnicity, $67 \%$ of participants identified as non-Hispanic White, $9 \%$ as Black or African American, and $7 \%$ as Other-i.e., Hispanic, Asian, Native American or Alaskan Native, Native Hawaiian or Pacific Islander, or Multiracial—and $17 \%$ preferred not to disclose their racial 
Table 1 WBI score mean, SD, and bivariate test by employee role $(\mathrm{n}=1,037)$

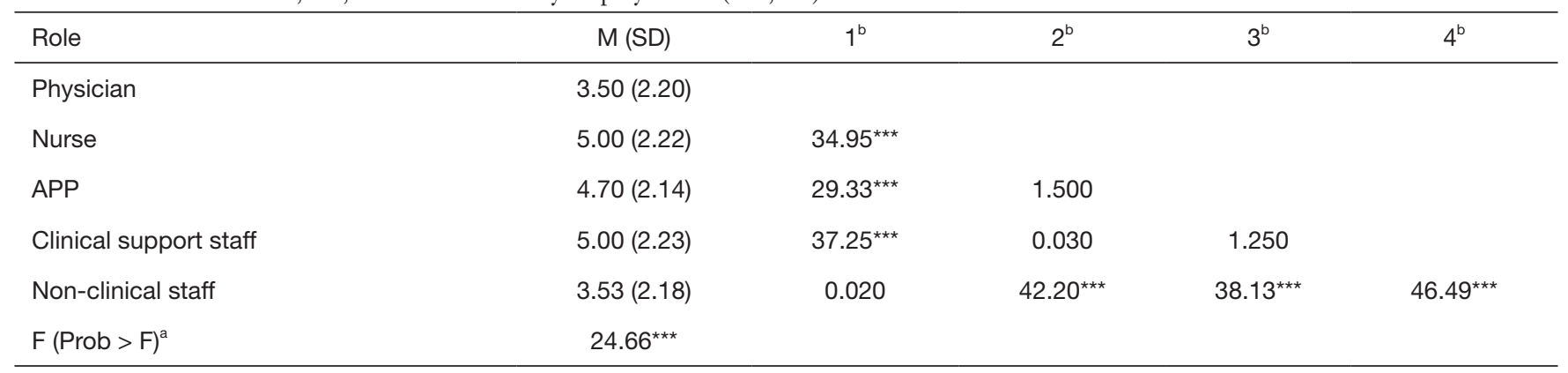

Data: survey collected by the authors. ${ }^{b}$, significance of ANOVA post-estimation test determining the difference in WBI score between employee roles; ' , significance of ANOVA tests determining the association between WBI score and employee role; ${ }^{\star \star \star}, \mathrm{P}<0.001$. WBI, Well-Being Index; SD, standard deviation; M, mean; APP, Advanced Practice Provider; ANOVA, analysis of variance.

and ethnic identity.

Table 1 presents parameter estimates-including means, $\mathrm{SD}$, and bivariate test results - of the outcome of employee distress as measured by the WBI for each employee category. On average, all employee categories exhibited high WBI distress scores and, as suggested in prior research, "the high distress" threshold is considered to be a WBI score greater or equal to two in the general employee population (32). Nurses (mean: 5.00; $\mathrm{SD}=2.22$ ) and Clinical support staff [mean: 5.00; standard error $(\mathrm{SE})=2.23$ ] had the highest WBI distress scores, whilst physicians had the lowest (mean: 3.50; $\mathrm{SD}=2.20$ ). An analysis of variance (ANOVA) test demonstrated that at least one of the employee group average WBI scores is different $(\mathrm{F}=24.66 ; \mathrm{P}<0.001)$. Postestimation testing showed physicians' average WBI was significantly lower than nurses $(\mathrm{F}=34.95 ; \mathrm{P}<0.001)$, APPs $(\mathrm{F}=29.33 ; \mathrm{P}<0.001)$, and Clinical support staff $(\mathrm{F}=37.25$; $\mathrm{P}<0.001)$. Non-clinical support staff's average WBI was significantly lower than nurses ( $\mathrm{F}=42.20 ; \mathrm{P}<0.001)$, APPs $(\mathrm{F}=38.13 ; \mathrm{P}<0.001)$ and Clinical support staff $(\mathrm{F}=46.49$; $\mathrm{P}<0.001)$. Tables 2-6 present multivariate linear regression models evaluating correlates of the WBI distress score for each employee group separately.

\section{Physicians}

Among physicians, those who showed high moral distress exhibited greater overall WBI distress scores $(\beta=0.324$; $\mathrm{P}<0.001$ ). According to our qualitative analysis, physicians' morale was reduced by their perceived inability to provide adequate patient care. Stress caused by increased job demands or responsibilities $(\beta=1.054 ; \mathrm{P}<0.001)$ and heavy workloads or long hours $(\beta=1.426, \mathrm{P}<0.001)$ was also associated with increased WBI distress levels. This was observed in numerous comments from physicians reporting that unnecessary responsibilities increased their workload and affected their well-being. Moreover, several physicians complained about the poor management of potential COVID positive patients and hospital employees. These sentiments may explain the higher rates of WBI distress among those that reported caring for critically ill COVID patients as a major stressor $(\beta=1.303 ; \mathrm{P}<0.05)$. As a rapidly implemented way to see patients remotely, adaptation to telemedicine was a significant stressor $(\beta=0.825 ; \mathrm{P}<0.001)$ because it came with additional obstacles affecting patientphysician interactions (e.g., connection process, app quality). That said, many physicians also commented that they believed telemedicine was a positive development in terms of patient access.

Having a better sense of work control $(\beta=-0.352$; $\mathrm{P}<0.05)$ was associated with lower WBI distress scores among physicians. Based on our qualitative findings, this association might be due to reduced bureaucracy and greater control of patient care-related responsibilities, and the established relationships between autonomy and positive motivational states. Personal resiliency was significantly associated with lower WBI distress scores $(\beta=-0.245 ; \mathrm{P}<0.01)$. Finally, those who reported high perceived organization support $(\beta=-0.100 ; \mathrm{P}<0.05)$ exhibited lower WBI distress scores. Though the majority of respondents critiqued leaders' performance, some physicians praised specific leaders who championed initiatives to address health disparities and the PPE shortage. Personal infection with COVID-19 was associated with lower WBI distress levels $(\beta=-0.898$; $\mathrm{P}<0.05)$, however, our qualitative data did not provide 
Table 2 Sample description and OLS regression predicting physicians' well-being score ( $\mathrm{n}=182)$

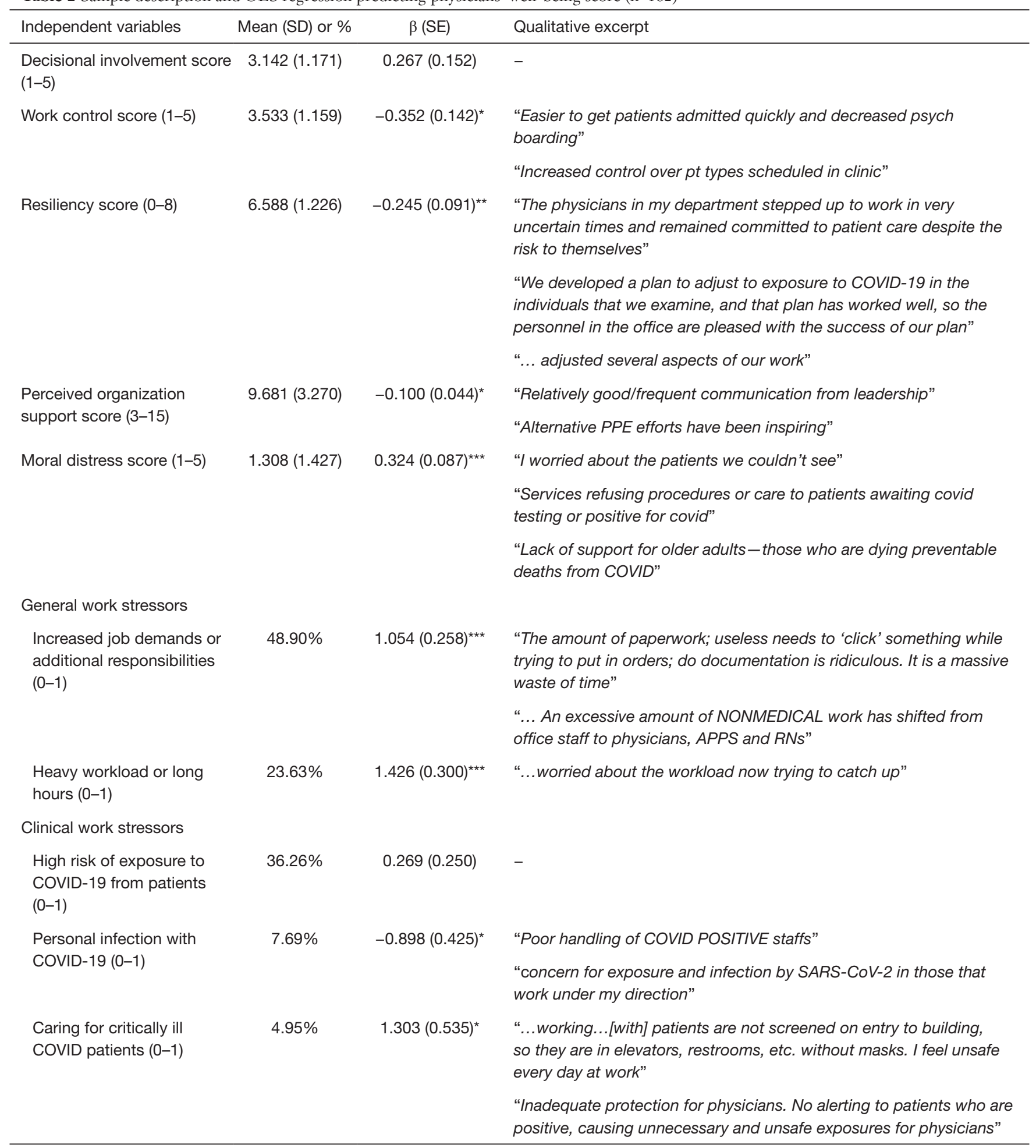

Table 2 (continued) 
Table 2 (continued)

\begin{tabular}{|c|c|c|c|}
\hline Independent variables & Mean (SD) or \% & $\beta$ (SE) & Qualitative excerpt \\
\hline \multirow{2}{*}{$\begin{array}{l}\text { Adapting to telemedicine } \\
(0-1)\end{array}$} & & & $\begin{array}{l}\text { "...hard to schedule inpatient from work flow standpoint, can be time } \\
\text { consuming" }\end{array}$ \\
\hline & & & $\begin{array}{l}\text { "Telemedicine app] needs a major overhaul or to be replaced. It has } \\
\text { constant connectivity issues, frequently invitations do not work, and } \\
\text { functionality is poor (screen sharing does not work). Virtual desktop } \\
\text { also needs an upgrade as there are frequent connectivity issues with } \\
\text { this service as well" }\end{array}$ \\
\hline $\begin{array}{l}\text { Total non-work stressors } \\
(1-14)\end{array}$ & $3.852(2.368)$ & $0.101(0.054)$ & - \\
\hline
\end{tabular}

Data: survey collected by the authors. *, $\mathrm{P}<0.05$; ${ }^{* \star}, \mathrm{P}<0.01$; ${ }^{* *}, \mathrm{P}<0.001$. OLS, ordinal least square; SD, standard deviation; $\beta$, coefficient; $\mathrm{SE}$, standard error; PPE, personal protective equipment.

context for this quantitative finding.

\section{Nurses}

Moral distress was associated with worse WBI scores among nurses $(\beta=0.171 ; \mathrm{P}<0.05)$. The nurses' comments suggest this association could have been due to not meeting their perceived responsibility to care for patients and their families. Moreover, understaffing issues increased these employees' workload, as portrayed in the quotes (see Table 3), which could potentially explain the detrimental effect of heavy workload on overall WBI distress ( $\beta$ $=1.401 ; \mathrm{P}<0.001)$. The shortage in staff forced hospital administration to reallocate front-line workers, especially nurses, to other departments or units to meet workforce needs of areas that were new or unknown to them. Hence, these abrupt changes in workflows or policies $(\beta=0.680$; $\mathrm{P}<0.05)$ took a toll on the nurses' well-being. According to our qualitative analysis, nurses felt the pandemic affected patient care due to decreased nurse-to-patient ratios or COVID-19 priorities. This may explain the relationship between nurses' higher WBI distress scores and reported feelings of stress related to the inability to provide high quality, patient- and family-centered care.

Although we saw a similar relationship between telemedicine stress and well-being among nurses $(\beta=1.423$; $\mathrm{P}<0.01)$ as that observed among physicians, it seemed to arise from a different reason. Nurses said they felt they had greater exposure to the virus while physically interacting with patients during the process of connecting their telemedicine calls with physicians. Other nurses critiqued the logistics behind telemedicine, including the connectivity speed, training, and patient acceptance. The positive association between home stressors and nurses' WBI distress scores $(\beta=0.196 ; \mathrm{P}<0.01)$ was in part explained by several comments in which they expressed their concerns of not being able to protect their loved ones from the virus or fulfill their family roles. Despite the effect of these stressors, team resiliency $(\beta=-0.123 ; \mathrm{P}<0.01)$ contributed to nurses' well-being and this is portrayed through several comments in which they praised their teams' ability to keep working regardless of the challenges.

Nurses reporting major stressors such as income reduction $(\beta=-0.597 ; \mathrm{P}<0.05)$, uncertainty in how to treat COVID-19 patients $(\beta=-1.236 ; \mathrm{P}<0.01)$, and racially related health disparities or other race/ethnicity issues as a clinical stressor $(\beta=-0.975 ; \mathrm{P}<0.05)$ had lower WBI distress scores. These findings were not supported qualitatively. According to our qualitative findings, nurses were upset with the mandatory salary decrements and saw this as an 
Table 3 Sample description and OLS regression predicting nurses' well-being score ( $\mathrm{n}=126)$

\begin{tabular}{|c|c|c|c|}
\hline Independent variables & Mean (SD) or \% & $\beta$ (SE) & Qualitative excerpts \\
\hline Team resiliency score $(0-15)$ & $11.492(2.944)$ & $-0.123(0.046)^{\star \star}$ & $\begin{array}{l}\text { "The limited business model has improved our team building. I have } \\
\text { found myself giving more compliments to my teammates and building } \\
\text { them up during this time of uncertainty" } \\
\text { "My peers have shown once again we can perform under pressure } \\
\text { despite poor leadership choices and an obvious lack of understanding of } \\
\text { the people upper leadership manages" } \\
\text { "I believe my coworkers and I have grown immensely as a team. We } \\
\text { were forced to overcome huge obstacles and teamwork was the only } \\
\text { way we could get through it" }\end{array}$ \\
\hline Moral distress score (1-5) & $1.865(1.703)$ & $0.171(0.084)^{*}$ & "... family expects us to know everything and call frequently" \\
\hline $\begin{array}{l}\text { Rapid change in workflows } \\
\text { or policies }(0-1)\end{array}$ & $66.67 \%$ & $0.680(0.282)^{*}$ & $\begin{array}{l}\text { "More consistency in the policies and practices with COVID-19 at [our } \\
\text { hospital]. The constant changes are increasing confusion and frustration" } \\
\text { "I would like it if expectations were clearer and that protocol was not } \\
\text { constantly changing. I feel like I cannot keep up" }\end{array}$ \\
\hline $\begin{array}{l}\text { Patients receiving poor } \\
\text { treatment }(0-1)\end{array}$ & $31.75 \%$ & $1.048(0.325)^{\star \star}$ & $\begin{array}{l}\text { "Concern that staff have forgotten what quality care and improved } \\
\text { outcome are because they are so worried about COVID-19. Patient care } \\
\text { has suffered" } \\
\text { "Better nurse/patient ratios and hiring more nurses and PCTs!! Taking } \\
\text { care of } 6 \text { patient with no help is exhausting, not to mention unsafe" }\end{array}$ \\
\hline $\begin{array}{l}\text { Uncertain how to treat } \\
\text { COVID-19 patients }(0-1)\end{array}$ & $20.63 \%$ & $-1.236(0.359)^{\star \star}$ & $\begin{array}{l}\text { "...being sent to other units outside my comfort zone" } \\
\text { "....sent to units where you are not trained" }\end{array}$ \\
\hline $\begin{array}{l}\text { Adapting to telemedicine } \\
(0-1)\end{array}$ & $10.32 \%$ & $1.423(0.449)^{\star \star}$ & $\begin{array}{l}\text { "Doctors should not rely on nurses to go into rooms for them when } \\
\text { telemedicine is not working" } \\
\text { "I know nursing staff received a brief training in service on it, but I think } \\
\text { additional sessions in conjunction with improved signal and doctor } \\
\text { education would be beneficial" }\end{array}$ \\
\hline
\end{tabular}

Table 3 (continued) 
Table 3 (continued)

\begin{tabular}{|c|c|c|c|}
\hline Independent variables & Mean (SD) or \% & $\beta$ (SE) & Qualitative excerpts \\
\hline $\begin{array}{l}\text { Total non-work stressors } \\
(1-14)\end{array}$ & $4.937(2.595)$ & $0.196(0.059)^{\star \star}$ & $\begin{array}{l}\text { "... keeping family healthy and covid free" } \\
\text { "Fear about infecting [my] family" } \\
\text { "...carrying covid home..." } \\
\text { "I had to constantly be on guard of how I interacted with my spouse } \\
\text { and child; very careful to only kiss my child on the back of the head and } \\
\text { keeping a safe distance as much as possible while home" } \\
\text { "I am extremely fearful on either contracting it and/or exposing my family } \\
\text { to it. I am filled with dread even thinking about potentially having to } \\
\text { isolate myself again from my family" }\end{array}$ \\
\hline
\end{tabular}

Data: survey collected by the authors. ${ }^{* *}, \mathrm{P}<0.01 ;{ }^{*}, \mathrm{P}<0.05 ;{ }^{* \star}, \mathrm{P}<0.001$. OLS, ordinal least square; SD, standard deviation; $\beta$, coefficient; SE, standard error.

unfair measure for healthcare workers who were at greatest risk of contracting COVID-19 from patients. Moreover, several nurses said they were sent to unfamiliar units and did not know how to provide care in that context, while others disagreed with the logistics of managing COVID-19 patients. Others expressed concern for racial inequalities in the healthcare system.

\section{APP}

Similar to other healthcare workers, APP's moral distress ( $\beta$ $=0.271 ; \mathrm{P}<0.01)$ was associated with increased WBI distress scores. Based on our qualitative findings, this relationship is explained by their inability to provide suitable patient care due to shortages in staff. The stress of increased job demands or responsibilities ( $\beta=0.944 ; \mathrm{P}<0.001)$ and heavy workload or long hours $(\beta=1.341 ; \mathrm{P}<0.001)$ was associated with higher WBI distress levels. One APP expanded on this association when they wrote about the staff shortage and how this phenomenon forced them to work extra hours and take on additional responsibilities. Among APPs' open responses about home stressors, we identified some regarding specific inner family issues, such as the death of a daughter and divorce, reflecting the detrimental effect of these non-work stressors on their overall well-being ( $\beta$ $=0.214 ; \mathrm{P}<0.001$ ).

On the other hand, APP's sense of decisional involvement $(\beta=-0.370 ; \mathrm{P}<0.001)$ was associated with lower WBI distress scores. Across multiple open-ended responses we saw how their inner team decision-making benefited their team. For example, one APP praised their coworkers' creativity to reduce the risk of exposure of their entire team, hence supporting the beneficial effect of being involved in decision making processes. The effect of personal resiliency followed a similar direction by lowering their WBI distress scores $(\beta=-0.273 ; \mathrm{P}<0.01)$. We observed the role of resiliency in comments portraying team-level adaptability to COVID-19 specific challenges. Reporting racially related health disparities or other ethnicity issues as major stressors was associated with lower WBI distress scores $(\beta=-0.917$; $\mathrm{P}<0.05)$. Not many within this group of healthcare workers wrote about this issue, and in the only comment associated with race the respondent showed their concern for the seriousness of this social problem.

\section{Clinical support staff}

Clinical support employees who reported high moral distress exhibited greater WBI distress scores $(\beta=0.429$; $\mathrm{P}<0.001)$ and similar to physicians we saw this detrimental effect through several comments where they shared feelings of guilt about being forced to provide poor patient care. As with nurses, Clinical support staff well-being was negatively associated with heavy workload stress $(\beta=1.361 ; \mathrm{P}<0.001)$, in part due to staff shortages. Furthermore, the stress of receiving a pay cut $(\beta=0.763 ; \mathrm{P}<0.01)$ and getting infected with COVID-19 $(\beta=0.988 ; \mathrm{P}<0.05)$ was associated with higher WBI distress. Clinical support staff who expressed 
Table 4 Sample description and OLS regression predicting APPs' well-being score $(\mathrm{n}=212)$

\begin{tabular}{|c|c|c|c|}
\hline Independent variables & Mean $(\mathrm{SD})$ or $\%$ & $\beta$ (SE) & Qualitative excerpts \\
\hline Resiliency score (0-8) & $6.858(1.139)$ & $-0.273(0.097)^{\star \star}$ & $\begin{array}{l}\text { "I feel that our staff and especially the clinical team has } \\
\text { been able to adapt with the changes. Mostly individuals } \\
\text { who have been present and continued to come to } \\
\text { work during the pandemic. It has been positive to see } \\
\text { some coworkers become more independent" } \\
\text { "I think we all adapted very quickly to ever changing } \\
\text { protocols and procedures" }\end{array}$ \\
\hline Perceived fairness/equity of pay cut (0-4) & $1.679(1.224)$ & $-0.148(0.093)$ & - \\
\hline General work stressors & & & \\
\hline $\begin{array}{l}\text { Increased job demands or additional } \\
\text { responsibilities }(0-1)\end{array}$ & $54.72 \%$ & $0.944(0.250)^{\star \star \star}$ & $\begin{array}{l}\text { "Mandatory overtime with lower income while being on } \\
\text { front lines with COVID positive patients..." }\end{array}$ \\
\hline Heavy workload or long hours $(0-1)$ & $37.26 \%$ & $1.341(0.248)^{\star \star \star}$ & $\begin{array}{l}\text { "We are constantly understaffed and being stretched } \\
\text { to perform all necessary responsibilities" }\end{array}$ \\
\hline $\begin{array}{l}\text { Racially related health disparities or other } \\
\text { ethnicity issues }(0-1)\end{array}$ & $10.85 \%$ & $-0.917(0.374)^{*}$ & $\begin{array}{l}\text { "new leadership that is not bias, full of clicks [sic] which } \\
\text { separate and cause division, or racially insensitive" }\end{array}$ \\
\hline Total non-work stressors (1-14) & $4.844(2.330)$ & $0.214(0.050)^{\star \star \star}$ & $\begin{array}{l}\text { "Death of Daughter" } \\
\text { "...separation \& divorce from spouse during pandemic" }\end{array}$ \\
\hline
\end{tabular}

Data: survey collected by the authors. ${ }^{\star \star \star}, \mathrm{P}<0.001$; ${ }^{\star \star}, \mathrm{P}<0.01 ;{ }^{*}, \mathrm{P}<0.05$. OLS, ordinal least square; APP, Advanced Practice Provider; SD, standard deviation; $\beta$, coefficient; SE, standard error.

their opinions towards the salary reduction thought it was an unfair decision for those who worked in the frontline and were at greater risk of contracting the virus.

Those who reported higher perceived organization support scores $(\beta=-0.094 ; \mathrm{P}<0.05)$ were less distressed. Clinical support employees were mixed in their opinions towards safety measures put in place by leaders as positive changes for their well-being. Those who worked remotely exhibited lower WBI distress scores $(\beta=-1.352 ; \mathrm{P}<0.01)$; however, working remotely made the task of separating work from home more difficult. Multiple clinical support staff members saw the ability to work remotely as a positive change because it lowered commuting stressors (e.g., traffic) and lowered the risk of furlough. 
Table 5 Sample description and OLS regression predicting Clinical support staff well-being score $(\mathrm{n}=157)$

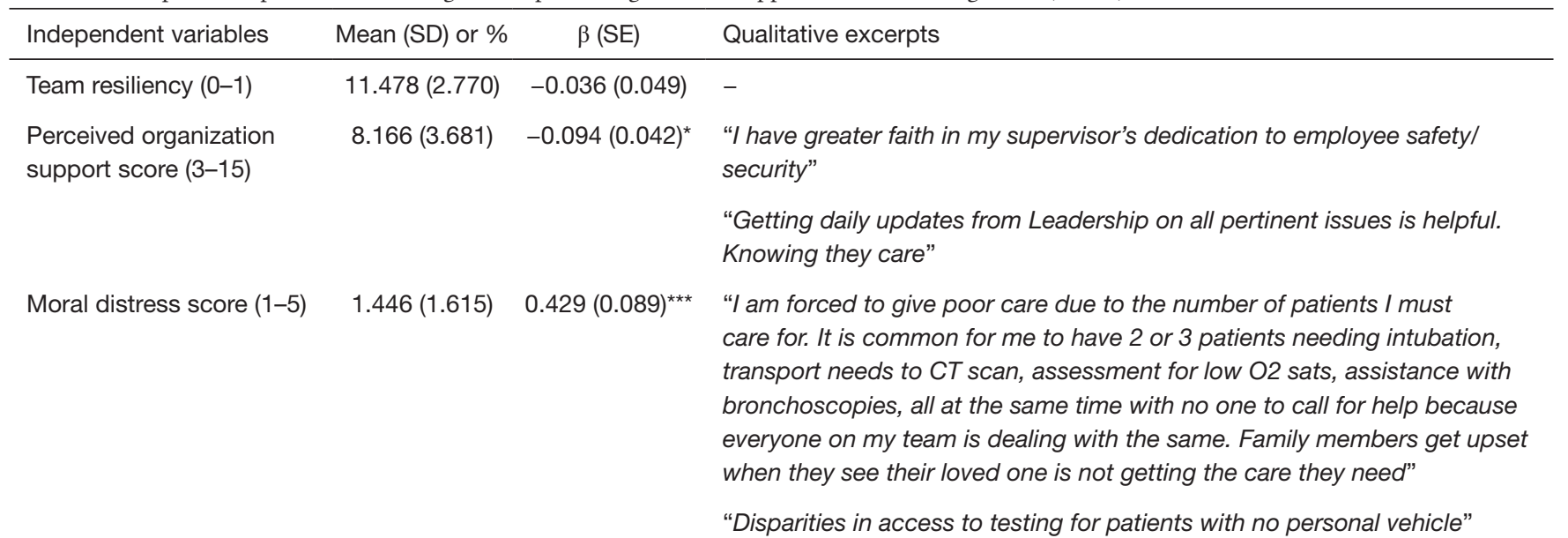

General work stressors hours $(0-1)$
Heavy workload or long

$48.41 \%$ $1.361(0.279)^{\star \star *}$

(1)
water. I was dehydrated and exhausted. We had 5 on our team and our workload called for 9 people. My BUN has been rising and my Dr. is concerned about my dehydration. I feel it is unhealthy for me to continue in my job at [HOSPITAL]"

"...concern over proper amount of staffing and their workloads"

"... reduced staffing with increased patient intake"

Scope of practice-unsure of adequate skills $(0-1)$

Working remotely $(0-1)$

$7.64 \%$

$4.46 \%$ $-0.986(0.636)$

$1.352(0.511)^{* \star}$

\section{"I think remote work (for those who can) is a positive change"}

"Covid has been the best thing to ever happen for my mental health. It has been a true break from all of the stresses in live (traffic, time at home with family, freedom to take off on a nice day and go for a hike, work my own hours, and meetings via zoom have allowed us to "cut to the chase" so meetings are not dragged out"

"The ability to work from home to keep people employed is a positive change"

"I do not believe that any pay reduction is fair. I strongly believe that reducing our pay is a direct insult to us and our families. We deserve to be treated better for the sacrifices we are making during this unprecedented time"

"I do not believe anyone in the clinical setting should have taken a pay cut. It's a slap in the face for us. We are working harder and more hours only to have a reduced pay for our shared efforts. I am very disappointed in how [HOSPITAL] has treated us in this pandemic"

Clinical work stressors

Personal infection with

"Also, inability to get COVID-19 screening test. Moreover, frustration that senior management did not thin to mobilize the basic science labs in things like screening and public education"
Total non-work stressors $(1-14)$

Data: survey collected by the authors. *, $\mathrm{P}<0.05 ;{ }^{* \star}, \mathrm{P}<0.01 ;{ }^{* \star}, \mathrm{P}<0.001$. OLS, ordinal least square; SD, standard deviation; $\beta$, coefficient; SE, standard error. 
Table 6 Sample description and OLS regression predicting Non-clinical staff well-being score $(\mathrm{n}=360)$

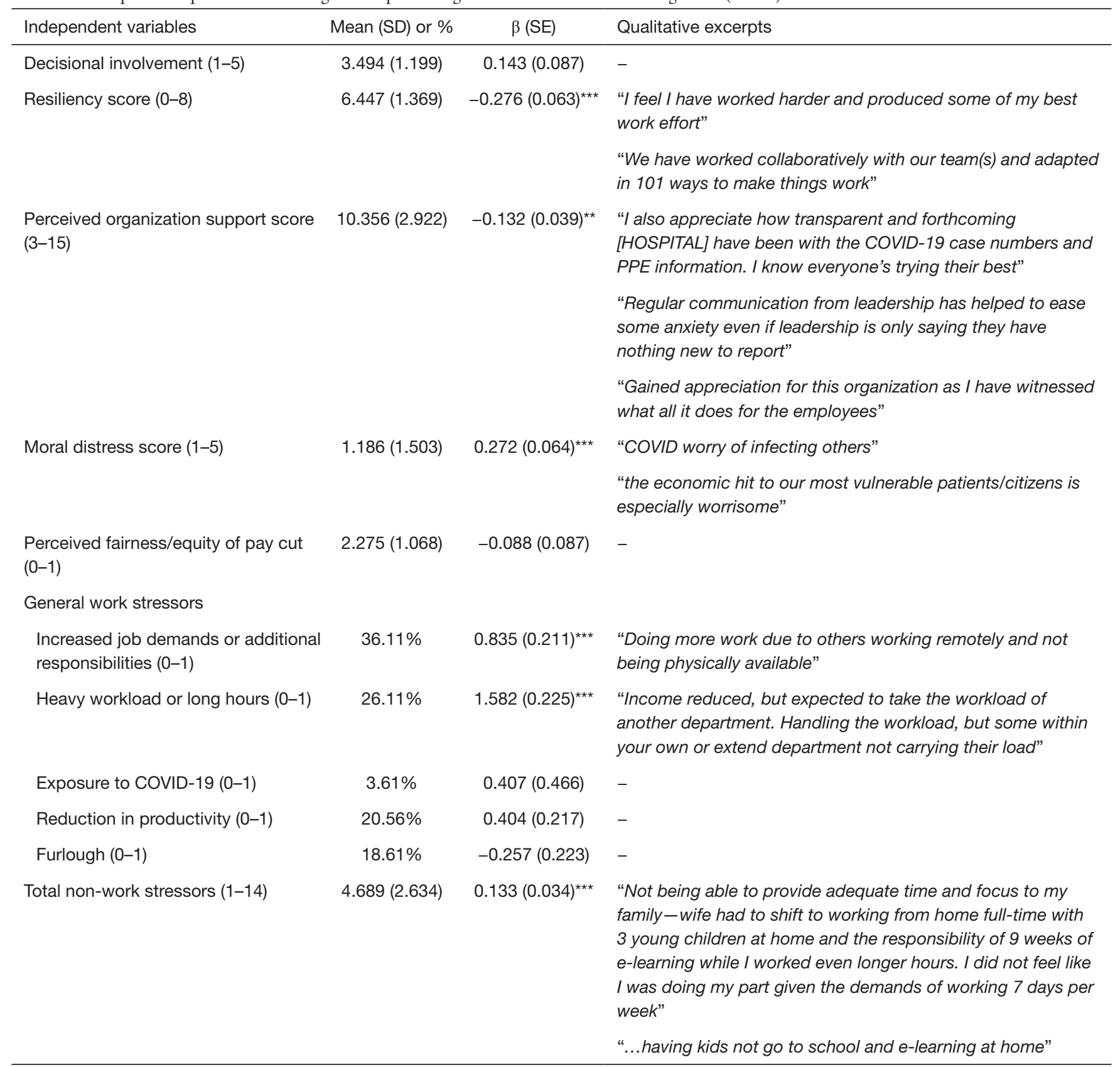

Data: survey collected by the authors. ${ }^{* *}, \mathrm{P}<0.001 ;{ }^{* *}, \mathrm{P}<0.01$. OLS, ordinal least square; SD, standard deviation; $\beta$, coefficient; $\mathrm{SE}$, standard error; PPE, personal protective equipment. 


\section{Non-clinical staff}

As with other employees, moral distress affected Nonclinical staff members' well-being $(\beta=0.272 ; \mathrm{P}<0.001)$. Among the opened-ended responses we identified two comments reflecting moral distress from worry about people in general. One respondent shared their concerns about infecting others, while another worried about the economic impact among vulnerable populations. Within specific work factors, the stress of having additional job demands or responsibilities $(\beta=0.835 ; \mathrm{P}<0.001)$ and juggling a heavy workload $(\beta=1.582 ; \mathrm{P}<0.001)$ were associated with greater overall WBI distress scores. Open-ended responses revealed that Non-clinical staff expressed that they were working longer hours compared to prior to the pandemic, either because the boundaries between work and home were blurred by remote working arrangements or because of increased job demands brought about by pandemic-related changes in the hospital. Despite working longer hours and working harder, the Non-clinical staff were also the targets of income reduction. Stressors outside of work also increased the level of WBI distress among these employees ( $\beta=0.133 ; \mathrm{P}<0.001$ ). Based on our qualitative analysis, most of these stressors were driven by spousal or parental role strains.

Similar to other employees, personal resiliency ( $\beta$ $=-0.276 ; \mathrm{P}<0.001)$ played a protective role among Nonclinical support staff. Those who provided an open-ended response said the conditions set by the pandemic triggered their ability to adapt to challenging work environments. Also, higher feelings of organizational support scores were associated with better well-being scores $(\beta=-0.132 ; \mathrm{P}<0.01)$. According to our qualitative findings, these employees appreciated the administration's effort to promote transparency and recognition of their own sacrifices.

\section{Discussion}

Overall, these results identify a broad array of stressors occurring simultaneously among members of the healthcare team during the COVID-19 pandemic. While the stressors differed by group, a common theme was that the majority of stressors that had a statistically significant association with distress were work-related factors. This is striking given the number of personal and societal stressors noted during this time. Non-clinical staff had lower distress compared to clinical staff (except for physicians). However, they showed lower resiliency and moral distress, as well as high decision involvement and feelings of organizational support compared to their clinical counterparts. In all models, work control and feelings of organizational support were inversely related to distress. This highlights the importance of creating healthy workplaces (including enhancing organizational resources for efforts supporting clinician well-being), and the relative role of work stress and home stress in driving overall distress and poor well-being. Next, we discuss the findings by professional groups.

\section{Physicians and APPs}

Few studies exist that address APPs' stress during COVID-19, and those that do have limited data analyses including small samples, thus APPs were combined and analyzed with either physicians or nurses $(43,44)$. Comparing these findings with other healthcare professions, we found similarities between APPs and physicians. Therefore, the discussion of APPs is incorporated with the discussion of physicians. The findings from our study resonated with other pandemic studies of health care worker well-being.

Perceived challenges within a global health crisis and stressful working conditions, including inadequate protection from contamination, high workload, isolation, patients' negative attitudes, and limited support from organizations, increase distress among physicians $(19,45,46)$. Wong and colleagues (47) examined the sources of distress among Hong Kong healthcare workers during the outbreak of severe acute respiratory syndrome (SARS) and found that loss of control, personal health, the spread of the virus, family and non-kin loved ones' health, changes in work, and isolation were the sources of distress which is congruent with the findings of this study. Therefore, understanding these factors is of value for healthcare organization planning and interventions aiming to reduce physicians' distress during the COVID-19 era and future pandemics.

While physicians who were stressed by the adaptation to telemedicine reported increased distress, this survey was conducted during the very early phases of implementing inpatient and expanded outpatient telemedicine at the hospital in the study. Additional research is needed to understand whether it is the use of telemedicine or just the initial implementation phase and adjustment to new processes and systems that was more taxing. Furthermore, many physicians also reported benefits of telemedicine, particularly in being able to expand patient access. For physicians, indicating that eldercare was a major stressor 
outside of work was associated with reduced overall distress, which is contrary to our initial expectations. However, this is not inconsistent with research that suggests that helping others actively improves one's well-being $(48,49)$. While eldercare may feel stressful, the caretaking of another may also actively work to reduce distress because of its intrinsic rewards (50).

\section{Nurses}

Nurses reported the highest average distress scores compared to all other professional groups in the same organization. This finding is also similar to prior work on the psychological impact of SARS outbreak on healthcare workers which found nurses reported highest overall distress levels compared to physicians and healthcare assistants (47). Given the amount of time nurses spend with patients at the bedside, it is not surprising that they may feel the effects of the crisis more deeply. The COVID-19 pandemic also raises the issues of moral distress and unexpected challenges to the moral and ethical values of nurses (51). The no-visitor policy weighed heavily on nurses who were taking care of patients, particularly in an inpatient setting. Nurses were often filling in the role of family, comforting the dying that were often alone in their rooms, while also performing their clinical duties. Nurses recognized that patients including those who were dying, were depressed and fearful, and attempted to support patients despite their heavy workloads (52). The findings of this study confirmed that higher moral distress was related to higher distress from the pandemic. The moral and ethical problems in the healthcare workplace are complex and require interprofessional work to guide future practice and education. In this pandemic, it is vital to capture lessons learned and explore the interventions or, if any, strategies that helped the staff cope with these moral injuries. Furthermore, hospital leaders should extend resources to improve mental health outcomes and prevent adverse mental disorders (e.g., post-traumatic stress disorder) among healthcare workers, especially nurses.

\section{Clinical support staff}

The findings of stress among Clinical support staff, such as patient care technicians, respiratory therapists and pharmacists, were similar to that of physicians and nurses, including significant associations between WBI distress and moral distress, feelings of organizational support, and heavy workload or long hours. However, in contrast to other groups, noting reduction in income as a major stressor was also significantly associated with overall distress. This may be reflective of the lower wages of this group relative to their Physician, Nurse, Non-clinical staff and APP counterparts. Clinical support staff reported that they felt guilty when being forced to provide poor patient care, particularly due to low staffing. Our study findings are similar to those noted in subsets of the Clinical support staff population. A study among healthcare providers emphasized that pharmacists were five times more likely to have perceived stress of COVID-19 as compared to physicians (53). This could also be due to differences in training among the different clinical roles. While physicians are likely personally exposed to a variety of diseases during the course of their medical residency training, other clinical staff may have had less exposure to these types of situations previously. One of the stress reduction strategies that was noted in the current study was resilience. This finding is congruent with another qualitative study in the US where pharmacists indicated effective communication from leadership and transparency regarding hospital responses and available resources for employee support reduced stress and promoted resilience (54). A study on respiratory therapists also confirmed that risk factors for burnout among this group is similar to other healthcare professionals including fear of becoming infected, fear of infecting loved ones, and emotional distress. The level of respiratory therapist burnout during COVID-19 was higher than before pandemic, and $68 \%$ reported inadequate support from their leaders, $31 \%$ reported high workload, and $29 \%$ reported insufficient staffing (55).

\section{Non-clinical employees}

Non-clinical employees seemed to have a greater sensitivity to the culture of the workplace, including feelings of organizational support. This is notable to mention, because despite also struggling with increasing workloads and long hours, Non-clinical employees likely missed much of the appreciation geared towards the frontline staff. It is also worth noting that moral distress was associated with greater WBI distress, as with the clinicians in this study. Healthcare managers and administrators can often be characterized negatively due to their focus on financial and operational goals amid a variety of external pressures and resource scarcity, which often puts them in the position of denying the wants and needs of different employee groups. During 
the pandemic, this group was responsible for securing PPE and testing, as well as making decisions about pay cuts and furloughs. For a leader to send their clinicians to the front lines knowing they are not able to provide adequate PPE or staff resources can also be a source of moral distress. Additionally, minimal studies exist that address Non-clinical staff stress during the pandemic, despite their importance to the larger healthcare team. In this study, Non-clinical staff reported that their stressors were from fear of infecting others, heavy workloads, and lack of organization support. These findings are congruent with a hospital staff study in Melbourne, Australia between April and May 2020 (56). Hospital staff require both managerial and psychological support to reduce their stress and improve both well-being and resilience in order to maintain their performance and quality of work during the COVID-19 crisis.

There were several surprising findings from our study, particularly regarding the quantitative relationships that were directionally opposite to what we expected. For example, nurses and APPs that reported racially related disparities in care as a major stressor also reported lower overall distress. It may be that reporting this issue as a major stressor is associated with some other unmeasured factor that may serve to lower distress, such as greater empathy or concern for injustice or community engagement (57-60). Nurses reporting uncertainty in how to treat COVID-19 patients also had lower overall distress, but these nurses may have been more likely to reach out to team members for help and questions which could have fostered an improved sense of teamwork, camaraderie or peer support. Lastly, reduced income for nurses was associated with reduced distress, which seems contrary to the qualitative results. Lastly, physicians that reported a personal infection with COVID-19 as a major stressor also had lower distress overall which was unusual. However, given the great degree of uncertainty about COVID-19 treatment early in the pandemic, those who were exposed and recovered may have felt a sense of relief from the dread of wondering whether they would have severe complications if COVID was contracted. In a sense, there may have been some relief that they already "got it over with". Our study is limited to the data collected via survey, but in-depth interviews and focus groups could be used in future work to disentangle these findings.

These findings ought to be interpreted in the light of several limitations. Our study included a convenience sample from one institution; hence results may not be generalizable to a larger population of healthcare employees and other organizations. Moreover, this study uses cross-sectional data, and we were unable to determine causality. Because of nonresponse biases, results may not be generalizable to employees from various demographic backgrounds. Finally, we assessed correlates of distress that should not be mistaken for job satisfaction, work engagement or stress.

Despite the previously mentioned limitations, this study benefits from several strengths. To our knowledge, we used the largest sample of healthcare employee data collected during the COVID-19 pandemic. Even though our findings do not account for contextual differences of other organizations, they capture institutional level correlates of distress. We combined quantitative and qualitative methodologies in a convergent mixed methods design to corroborate the accuracy of findings from both strands of the study.

Overall, an important theme across groups is that building resilience, and reducing heavy workload and moral distress are universally important components of wellbeing. Furthermore, feelings of organizational support were associated with lower distress in most groups. These represent important targets for organizational interventions aimed at improving well-being. However, this study also demonstrates that while some correlates of well-being extend across groups, there are unique differences within various employee sub-groups within a healthcare setting. These findings can help leaders develop more targeted interventions to specific groups.

\section{Conclusions}

The tragedies witnessed during the COVID-19 pandemic along with a wealth of work and non-work related stressors are likely to leave deep psychological scars among healthcare providers. This calls for new ways of adapting to and thinking about this crisis; including expanding access to trauma-related mental healthcare for all healthcare providers, Clinical support staff, and NonClinical employees in an ongoing manner and even into the future as the magnitude of the pandemic decreases. Posttraumatic stress disorder, compassion fatigue, and secondary traumatic stress are likely outcomes among healthcare professionals across the entire team during the COVID-19 pandemic. Healthcare organizations should develop mechanisms to identify specific sources of distress within different employee sub-groups, and should design tailored interventions to address their unique causes. A one-size- 
fits-all solution is unlikely to meet the diverse needs of the healthcare workforce.

\section{Acknowledgments}

Funding: This study was funded by a grant from the ProAssurance Corporation, awarded to DAR.

\section{Footnote}

Provenance and Peer Review: This article was commissioned by the editorial office, Journal of Hospital Management and Health Policy for the series "Shaping Tomorrow's Healthcare Systems: Key Stakeholders' Expectations and Experiences”. The article has undergone external peer review.

Reporting Checklist: The authors have completed the SURGE reporting checklist. Available at https://jhmhp. amegroups.com/article/view/10.21037/jhmhp-21-69/rc

Data Sharing Statement: Available at https://jhmhp. amegroups.com/article/view/10.21037/jhmhp-21-69/dss

Peer Review File: Available at https://jhmhp.amegroups.com/ article/view/10.21037/jhmhp-21-69/prf

Conflicts of Interest: All authors have completed the ICMJE uniform disclosure form (available at https://jhmhp. amegroups.com/article/view/10.21037/jhmhp-21-69/coif). The series "Shaping Tomorrow's Healthcare Systems: Key Stakeholders' Expectations and Experiences" was commissioned by the editorial office without any funding or sponsorship. KAM served as an unpaid Guest Editor of the series. DAR received a grant from ProAssurance Corporations. The authors have no other conflicts of interest to declare.

Ethical Statement: The authors are accountable for all aspects of the work in ensuring the questions related to the accuracy or integrity of any part of the work are appropriately investigated and resolved. This study was conducted in accordance with the Declaration of Helsinki (as revised in 2013). This study was approved by the Institutional Review Board of the University of Alabama at Birmingham (No. IRB-300005398) and informed consent was taken from all of the participants.

Open Access Statement: This is an Open Access article distributed in accordance with the Creative Commons Attribution-NonCommercial-NoDerivs 4.0 International License (CC BY-NC-ND 4.0), which permits the noncommercial replication and distribution of the article with the strict proviso that no changes or edits are made and the original work is properly cited (including links to both the formal publication through the relevant DOI and the license). See: https://creativecommons.org/licenses/by-nc-nd/4.0/.

\section{References}

1. Brandford AA, Reed DB. Depression in Registered Nurses: A State of the Science. Workplace Health Saf 2016;64:488-511.

2. Merlo LJ, Gold MS. Prescription opioid abuse and dependence among physicians: hypotheses and treatment. Harv Rev Psychiatry 2008;16:181-94.

3. Epstein PM, Burns C, Conlon HA. Substance abuse among registered nurses. AAOHN J 2010;58:513-6.

4. Oreskovich MR, Shanafelt T, Dyrbye LN, et al. The prevalence of substance use disorders in American physicians. Am J Addict 2015;24:30-8.

5. Shanafelt TD, Boone S, Tan L, et al. Burnout and satisfaction with work-life balance among US physicians relative to the general US population. Arch Intern Med 2012;172:1377-85.

6. Čartolovni A, Stolt M, Scott PA, et al. Moral injury in healthcare professionals: A scoping review and discussion. Nurs Ethics 2021;28:590-602.

7. Shah MK, Gandrakota N, Cimiotti JP, et al. Prevalence of and Factors Associated With Nurse Burnout in the US. JAMA Netw Open 2021;4:e2036469.

8. Dewa CS, Loong D, Bonato S, et al. How does burnout affect physician productivity? A systematic literature review. BMC Health Serv Res 2014;14:325.

9. Shanafelt TD, Mungo M, Schmitgen J, et al. Longitudinal Study Evaluating the Association Between Physician Burnout and Changes in Professional Work Effort. Mayo Clin Proc 2016;91:422-31.

10. Dyrbye LN, Shanafelt TD, Johnson PO, et al. A crosssectional study exploring the relationship between burnout, absenteeism, and job performance among American nurses. BMC Nurs 2019;18:57.

11. Hall LH, Johnson J, Watt I, et al. Healthcare Staff Wellbeing, Burnout, and Patient Safety: A Systematic Review. PLoS One 2016;11:e0159015.

12. Dewa CS, Loong D, Bonato S, et al. The relationship between physician burnout and quality of healthcare in 
terms of safety and acceptability: a systematic review. BMJ Open 2017;7:e015141.

13. Tawfik DS, Profit J, Morgenthaler TI, et al. Physician Burnout, Well-being, and Work Unit Safety Grades in Relationship to Reported Medical Errors. Mayo Clin Proc 2018;93:1571-80.

14. Ashill NJ, Rod M. Burnout processes in non-clinical health service encounters. J Bus Res 2011;64:1116-27.

15. Cagnazzo C, Filippi R, Zucchetti G, et al. Clinical research and burnout syndrome in Italy - only a physicians' affair? Trials 2021;22:205.

16. Allan SM, Bealey R, Birch J, et al. The prevalence of common and stress-related mental health disorders in healthcare workers based in pandemic-affected hospitals: a rapid systematic review and meta-analysis. Eur J Psychotraumatol 2020;11:1810903.

17. The Physician Foundation. The Physician Foundation 2020 Physcial Survey: Part 2.

18. SE Healthcare Performance Analytics \& Solutions. The impact of physician burnout before COVID-19, 2021. Available online: https://www. sehealthcarequalityconsulting.com/2021/02/03/theimpact-of-physician-burnout-before-covid-19/

19. Shanafelt T, Ripp J, Trockel M. Understanding and Addressing Sources of Anxiety Among Health Care Professionals During the COVID-19 Pandemic. JAMA 2020;323:2133-4.

20. Frogner BK, Skillman SM. The Challenge in Tracking Unemployment Among Health Care Workers and Why It Matters. JAMA Heal Forum 2020;1:e201358.

21. Banerjee D, Rai M. Social isolation in Covid-19: The impact of loneliness. Int J Soc Psychiatry 2020;66:525-7.

22. Jacobs A. A parallel pandemic hits health care workers: trauma and exhaustion. The New York Times 2021.

23. Stokel-Walker C. Why telemedicine is here to stay. BMJ 2020;371:m3603.

24. Batra K, Singh TP, Sharma M, et al. Investigating the Psychological Impact of COVID-19 among Healthcare Workers: A Meta-Analysis. Int J Environ Res Public Health 2020;17:9096.

25. JHUM. COVID-19 Dashboard by the center for Systems Science and Engineering (CSSE). Coronvrus Resource Center at Johns Hopkins Univeristy \& Medicine 2021. Available online: https://coronavirus.jhu.edu/map.html

26. CDC. Cases \& Deaths among Healthcare Personnel. Center for Disease Control and Prevention 2021. Available online: https://covid.cdc.gov/covid-data-tracker/\#healthcare-personnel
27. Meese KA, Colón-López A, Singh JA, et al. Healthcare is a Team Sport: Stress, Resilience, and Correlates of WellBeing Among Health System Employees in a Crisis. J Healthc Manag 2021;66:304-22.

28. Morse JM, Niehaus L. Mixed methods design: Principles and procedures. Walnut Creek, CA, USA: Left Coast Press, 2009.

29. Collins KM. Advanced sampling designs in mixed research: Current practices and emerging trends in the social and behavioral sciences. In: Tashakkori A, Teddlie C. editors. Sage handbook of mixed methods in social and behavioral research. 2nd edition. Thousand Oaks, CA, USA: Sage, 2010.

30. Greene JC, Caracelli VJ, Graham WF. Toward a concptual framework for mixed-method evaluation designs. Educ Eval Policy Anal 1989;11:255-74.

31. Dyrbye LN, Satele D, Sloan J, et al. Utility of a brief screening tool to identify physicians in distress. J Gen Intern Med 2013;28:421-7.

32. Dyrbye LN, Satele D, Shanafelt T. Ability of a 9-Item Well-Being Index to Identify Distress and Stratify Quality of Life in US Workers. J Occup Environ Med 2016;58:810-7.

33. Beresin EV, Milligan TA, Balon R, et al. Physician Wellbeing: A Critical Deficiency in Resilience Education and Training. Acad Psychiatry 2016;40:9-12.

34. U.S. Department of Venterans Affairs. National center for organizational development. VA All Employee Survey 2018.

35. Fisher GG, Matthews RA, Gibbons AM. Developing and investigating the use of single-item measures in organizational research. J Occup Health Psychol 2016;21:3-23.

36. Eisenberger R, Cummings J, Armeli S, et al. Perceived organizational support, discretionary treatment, and job satisfaction. J Appl Psychol 1997;82:812-20.

37. Vaishnavi S, Connor K, Davidson JR. An abbreviated version of the Connor-Davidson Resilience Scale (CDRISC), the CD-RISC2: psychometric properties and applications in psychopharmacological trials. Psychiatry Res 2007;152:293-7.

38. Sharma S, Sharma SK. Team Resilience: Scale Development and Validation. Vis J Bus Perspect 2016;20:37-53.

39. StataCorp. Stata Statistical Software. StataCorp LLC 2019.

40. QSR International. NVivo. QSR International Pty Ltd 2019.

41. Lofland J, Snow D, Anderson L, Lofland H. Analyzing social settings: a guide to qualitative observation and 
analysis. Belmont, CA, USA: Thomson/Wadsworth, 2006.

42. Curry L, Nunez-Smith M. Mixed methods in health sciences research: A practical primer. Thousand Oaks, CA, USA: SAGE Publications, 2015.

43. Shechter A, Diaz F, Moise N, et al. Psychological distress, coping behaviors, and preferences for support among New York healthcare workers during the COVID-19 pandemic. Gen Hosp Psychiatry 2020;66:1-8.

44. Kelker H, Yoder K, Musey P Jr, et al. Prospective study of emergency medicine provider wellness across ten academic and community hospitals during the initial surge of the COVID-19 pandemic. BMC Emerg Med 2021;21:36.

45. Zeng X, Peng T, Hao X, et al. Psychological Distress Reported by Primary Care Physicians in China During the COVID-19 Pandemic. Psychosom Med 2021;83:380-6.

46. Berg S. 4 ways COVID-19 is causing moral distress among physicians. American Medical Association 2020. Available online: https://www.ama-assn.org/practice-management/ physician-health/4-ways-covid-19-causing-moral-distressamong-physicians

47. Wong TW, Yau JK, Chan CL, et al. The psychological impact of severe acute respiratory syndrome outbreak on healthcare workers in emergency departments and how they cope. Eur J Emerg Med 2005;12:13-8.

48. Dissanayake I, Nerur S, Wang J, et al. The Impact of Helping Others in Coopetitive Crowdsourcing Communities. J Assoc Inf Syst 2021;22:67-101.

49. Spitzmuller M, Park G, Van Dyne L, et al. When do you benefit? Differential boundary conditions facilitate positive affect and buffer negative affect after helping others. Eur J Work Organ Psychol 2021;30;482-94.

50. Bangerter LR, Griffin JM, Dunlay SM. Positive Experiences and Self-Gain Among Family Caregivers of Persons With Heart Failure. Gerontologist 2019;59:e433-40.

doi: 10.21037/jhmhp-21-69

Cite this article as: Colón-López A, Meese KA, Montgomery AP, Patrician PA, Rogers DA, Burkholder GA. Unique stressors in a global pandemic: a mixed methods study about unique causes of distress among healthcare team members during COVID-19. J Hosp Manag Health Policy 2022;6:23.
51. Turale S, Meechamnan C, Kunaviktikul W. Challenging times: ethics, nursing and the COVID-19 pandemic. Int Nurs Rev 2020;67:164-7.

52. LoGiudice JA, Bartos S. Experiences of Nurses During the COVID-19 Pandemic: A Mixed-Methods Study. AACN Adv Crit Care 2021;32:14-26.

53. Chekole YA, Yimer Minaye S, Mekonnen Abate S, et al. Perceived Stress and Its Associated Factors during COVID-19 among Healthcare Providers in Ethiopia: A Cross-Sectional Study. Adv Public Heal 2020;2020:1-7.

54. Norful AA, Rosenfeld A, Schroeder K, et al. Primary drivers and psychological manifestations of stress in frontline healthcare workforce during the initial COVID-19 outbreak in the United States. Gen Hosp Psychiatry 2021;69:20-6.

55. L Evans D. The Impact of COVID-19 on Respiratory Therapist Burnout. Respir Care 2021;66:881-3.

56. Digby R, Winton-Brown T, Finlayson F, et al. Hospital staff well-being during the first wave of COVID-19: Staff perspectives. Int J Ment Health Nurs 2021;30:440-50.

57. Duarte J, Pinto-Gouveia J, Cruz B. Relationships between nurses' empathy, self-compassion and dimensions of professional quality of life: A cross-sectional study. Int J Nurs Stud 2016;60:1-11.

58. Narme P. Burnout in nursing staff caring for patients with dementia: role of empathy and impact of empathy-based training program. Geriatr Psychol Neuropsychiatr Vieil 2018;16:215-22.

59. Haghighinezhad G, Atashzadeh-Shoorideh F, Ashktorab T, et al. Relationship between perceived organizational justice and moral distress in intensive care unit nurses. Nurs Ethics 2019;26:460-70.

60. Lawrence LA. Work engagement, moral distress, education level, and critical reflective practice in intensive care nurses. Nurs Forum 2011;46:256-68. 